\title{
Solidification Furnace Developed for Sounding Rockets: Rio Verde Mission
}

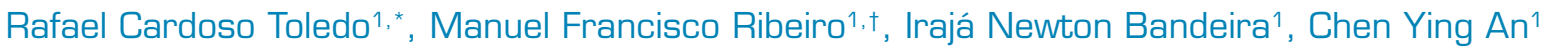

How to cite

Toledo RC iD https: / /orcid.org/0000-0002-1114-198X

Bandeira IN (iD https://orcid.org/0000-0002-7750-5563

An CY (D) https://orcid.org/0000-0002-9559-8046
Toledo RC; Ribeiro MF; Bandeira IN: An CY (2019) Solidification Furnace Developed for Sounding Rockets: Rio Verde Mission. J Aerosp Technol Manag, 11: e2519. https://doi.org/10.5028/ jatm.v11.1140

ABSTRACT: Brazil has a Microgravity Program mainly based on experiments using sounding rockets. Up to now, four missions have been carried out with approximately 35 experiments submitted in total. In all flights, the Associate Laboratory of Sensors and Materials of the Brazilian Space Research Institute (LABAS/INPE) participated with a fast solidification furnace, capable of producing temperatures up to $900{ }^{\circ} \mathrm{C}$, which was tested with semiconductor and metal alloys. This paper describes the construction and the performance of that furnace during the last parabolic flight, Rio Verde Mission, occurred in 2016. solidification furnace is now qualified and ready to be used by other institutions in sounding rocket flights.

KEYWORDS: Microgravity, Brazilian sounding rocket, Solidification furnace.

\section{INTRODUCTION}

Microgravity is a powerful tool for better understanding fundamental questions of science in order to find solutions to terrestrial problems. In this way, it allows optimizing and improving physical, chemical and biological processes that are important in science, engineering and medicine. The use of microgravity began in the early years of space programs, with experiments aboard Apollo, Skylab, and Apollo-Soyus during the 1960s and 1970s (Naumann and Herring 1980; Hamacher et al. 1987). Because it is considered a strategic area of research, in Brazil the National Program of Space Activities (PNAE) provides guidelines and priority actions that seek to develop critical technology and research in microgravity, training and training specialists in space activities (AEB 2012).

The Brazilian Microgravity Program was established in 1998 by the Brazilian Space Agency (AEB), aimed to provide a regular sequence of flight opportunities for the Brazilian scientific community to carry out experiments and test the hardware of installations in a microgravity environment. The Program supports the Brazilian microgravity activities by selecting and monitoring, through institutions such as the Brazilian Space Research Institute (INPE) and the Aeronautics and Space Institute (IAE), the experiences from its initial phases of the project to the flight mission, also providing partial financial support for the approved projects (http://www.aeb.gov.br).

The Program contemplates missions on ISS/Soyuz and on Brazilian made sounding rockets. Up to now, only one flight was made at ISS in 2006, carrying eight experiments and the first Brazilian astronaut (Bandeira et al. 2007). Four parabolic flights were made by Brazilian rockets (VS-30 and VSB-30) built by IAE and launched from the Alcântara Launching Center (CLA), in northeast Brazil (An et al. 2011; 2012; 2014; Garcia et al. 2011; Toledo 2013).

1. Instituto Nacional de Pesquisas Espaciais - Coordenadoria de Tecnologias Espaciais - Laboratório Associado de Sensores e Materiais - São José dos Campos/SP - Brazil.

$\dagger$ In Memoriam

*Correspondence author: toledo.rc@gmail.com

Received: May 24, 2018 | Accepted: Sep. 3, 2018

Section Editor: José Ferreira 
The Brazilian VSB-30 rocket is based on the VS-30 rocket (S-30 engine) with the addition of a booster stage (S-31 engine). It is capable of transporting payloads with mass up to $400 \mathrm{~kg}$ during about $360 \mathrm{~s}$ in a ballistic flight above $300 \mathrm{~km}$, it has a liftoff thrust of $240 \mathrm{kN}$ and a total mass of $2570 \mathrm{~kg}$. The rocket transports a payload based in the TEXUS technology, made by DLR/MORABA in cooperation with IAE, used to monitoring the flight, into a nominal trajectory. The VSB-30 rockets replaced the Skylark rocket in Esrange Space Center in Sweden from 2005 (Garcia et al. 2011; Toledo 2013).

The area of materials science is one of those that benefit most from the microgravity environment. This includes studies on immiscible, eutectic materials, morphological development during solidification, nucleation phenomena, isothermal dendritic growth, macro-segregation and the behavior of the insoluble particles ahead of the solidification interface. In Brazil, there are few multiuser facilities (including a multiuser high temperature furnace built in the INPE) able to provide the appropriate conditions of temperature, thermal gradient and controlled cooling, for processing, solidification and growth of crystals and materials inorganic acids (Naumann and Herring 1980; Hamacher et al. 1987; Toledo 2013).

\section{SOLIDIFICATION FURNACE}

The objective was to project, construct and qualify a multi-user microgravity compact solidification furnace for low temperature operation $\left(100\right.$ to $300^{\circ} \mathrm{C}$ ) as a permanent facility to the sounding rockets microgravity program. The proposal was made by a group of the Associate Laboratory of Sensors and Materials (LAS) of the Brazilian Space Research Institute (INPE). The furnace should be capable of a fast cooling, compatible with the short microgravity times of suborbital flights, in order to solidify six samples up to $9 \mathrm{~mm}$ diameter and up to $100 \mathrm{~mm}$ length. The scientific part of the project contemplates the continuity of the study of the microgravity influence on the homogeneity of the composition and microstructure of eutectic alloys.

AEB uses VSB-30 sounding rocket made by IAE. These vehicles are launched at the Alcântara Launch Center (CLA), thus the operation scenario available molded the furnace project structure. The project is composed of two modules: suborbital module and terrestrial module. The suborbital module accommodates the furnace assembly and the electronic rocket unit (UEFOG), responsible for motor control, furnace and data acquisition, and Ni-MH batteries. The terrestrial module accommodates the power supply (UEFONTE), which supplies the power requirement for heating the furnace and recharging the UEFOG batteries, as well as the electronic control unit of the bunker (UECAS), which allows the operator to monitor and control the system (Fig. 1).
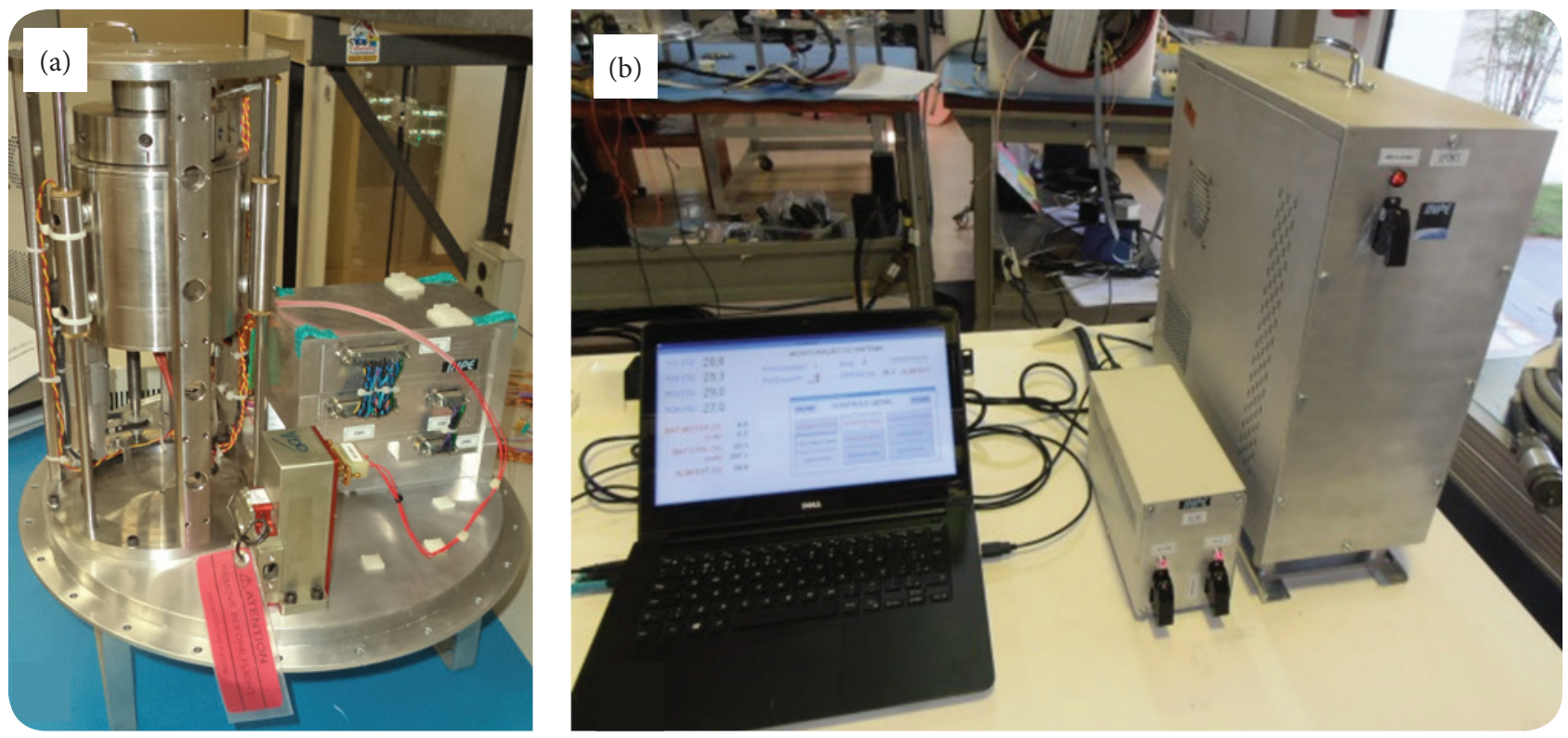

Figure 1. (a) Furnace and UEFOG; and (b) UEFONTE, UECAS and notebook. 
The module volumes are installed in three different places: suborbital module in the sounding rocket; UEFONTE in the electric panel near the launcher; and the UECAS in the bunker (Fig. 2).

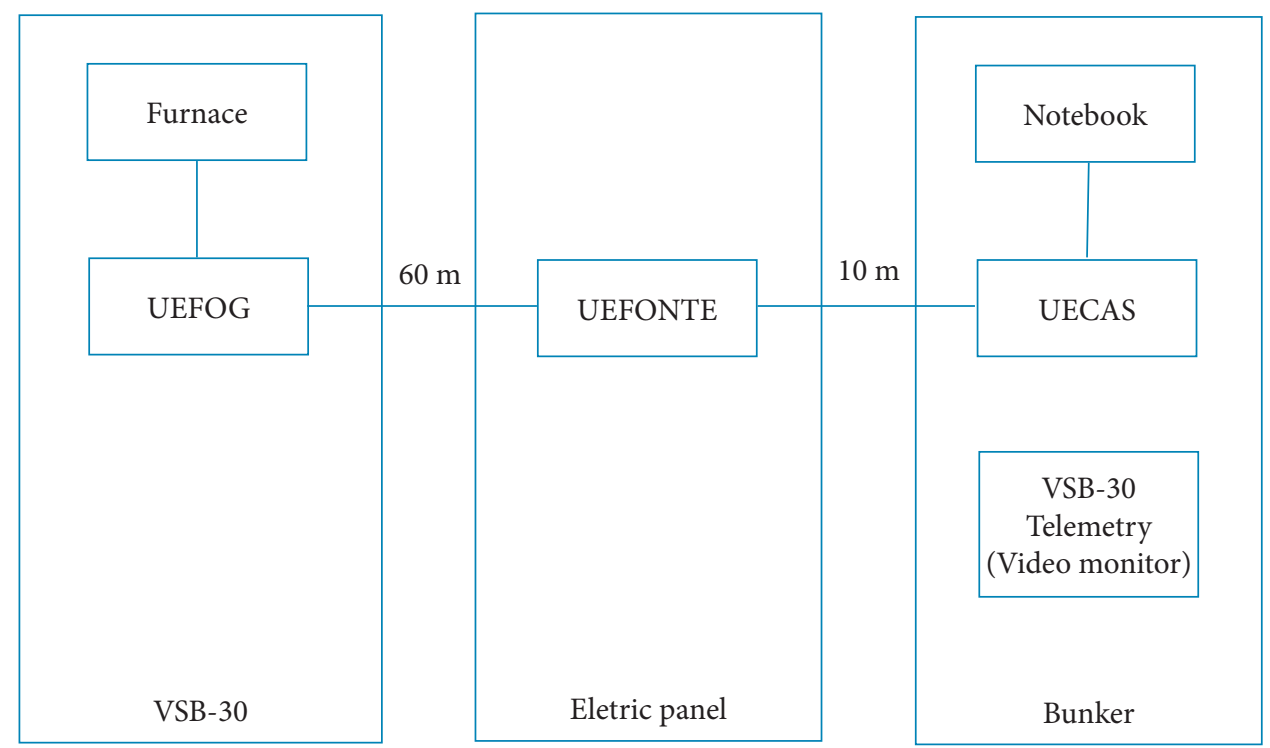

Figure 2. Block diagram of the electronic system, showing the locations where the components meet.

The tubular furnace is heated and controlled from the ground through the rocket umbilical cable until it reaches the desired temperature. After launch, the temperature is kept by thermal inertia. When the microgravity environment is reached, a signal starts the movement of the hot part of the furnace and a fast sample cooling is obtained. The experiment temperature is monitored by three thermocouples and their signals are stored in an internal data logger as well as sent to ground by telemetry.

The drawing of the furnace is shown on Fig. 3. It comprises the tubular furnace itself made of stainless steel, having $120 \mathrm{~mm}$ length, $127 \mathrm{~mm}$ of external diameter and $59 \mathrm{~mm}$ of internal diameter; the space between the walls of the tube is filled
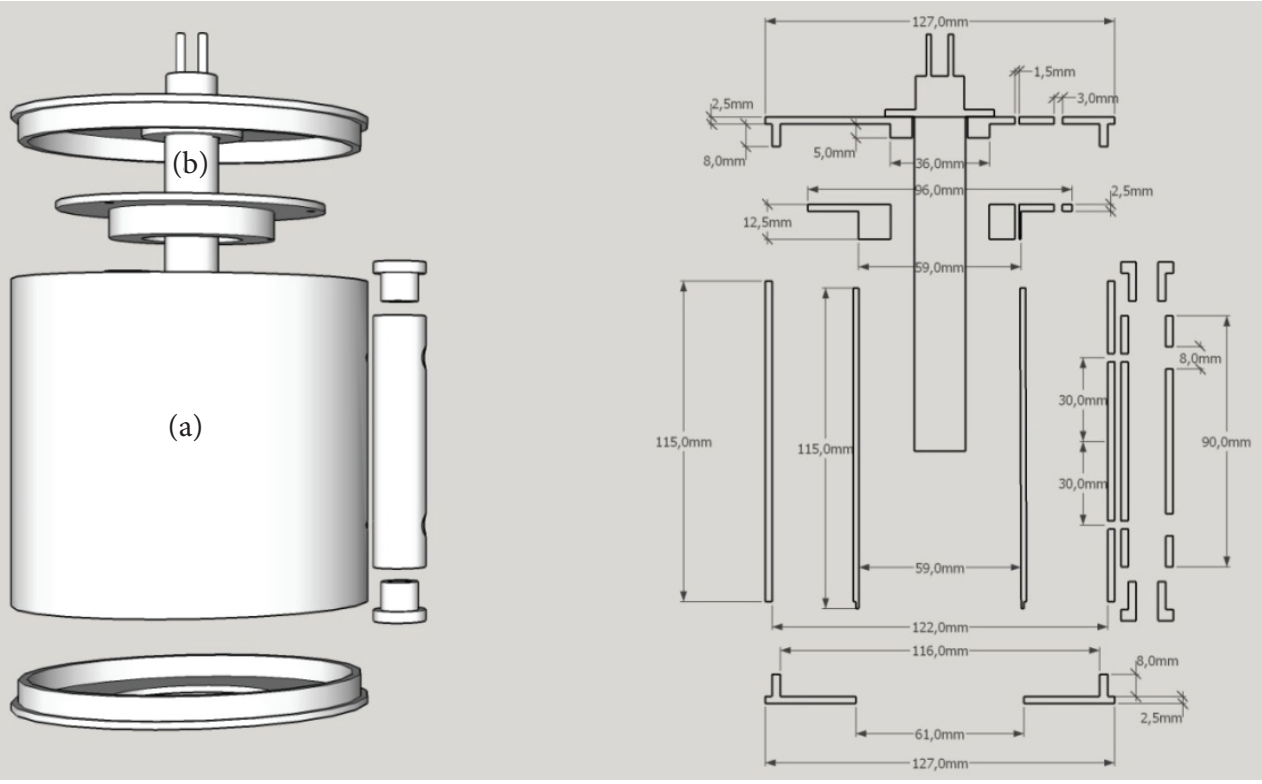

Figure 3. Description of the tubular furnace: (a) furnace, and (b) resistance. 
with quartz fiber, which is employed as thermal insulation. The materials are processed inside the internal cavity of the tube, which has a shielded nickel-chromium resistance $(15 \Omega-150 \mathrm{~W})$ fixed to the top that runs throughout its length. There is an external structure holding the furnace, permitting it's up and down movement with the aid of an electric motor. This structure also supports a stainless steel sample holder placed inside the cavity of the tube. The system has a total diameter of $180 \mathrm{~mm}$ and a total length of $340 \mathrm{~mm}$, weighting $10 \mathrm{~kg}$.

The drawing of the furnace system (Fig. 4) shows the details of the displacement system, composed of the following elements: (1) furnace, (2) spindle, (3) DC motor, (4) transmission/reduction box, (5) sliding rods, (6) securing rods, and (7) sample holders. Figure 5 shows details and measurements of the sample holder and its attachment to the furnace system.

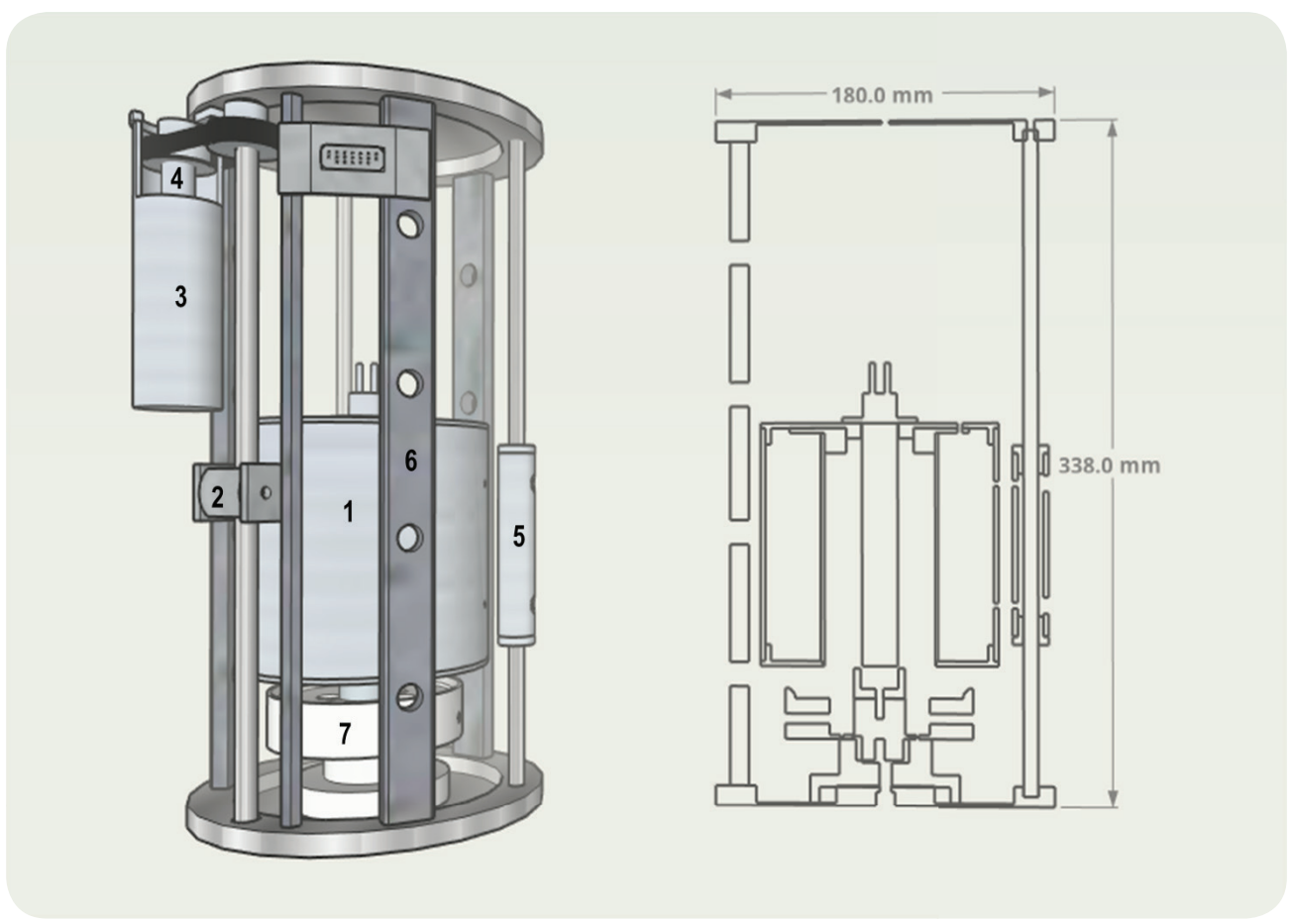

Figure 4. Description of the furnace system: (1) furnace, (2) spindle, (3) DC motor, (4) transmission/reduction box, (5) sliding rods, (6) securing rods, and (7) sample holders.

The DC motor (3), powered by its own $4.8 \mathrm{~V}$ batteries, is coupled to the spindle (2) by a transmission system (4), allowing the oven to be moved when necessary. The drive of the motor and consequent displacement of the furnace occurs upon receipt of a signal indicating the beginning of the period of microgravity given by the platform. The furnace is then moved until it reaches the end of the stroke, controlled by a limit switch.

Figure 6 shows the furnace in the two positions described above. During ground and ascending rocket phase the furnace is at the bottom position, completely involving and heating the sample. As soon as the microgravity environment is reached, the motor drives de furnace to the upper position in less than $13 \mathrm{~s}$, leaving the sample exposed to cool down.

In order to meet the PNAE proposals, the electronic project privileged the use of national components to qualify them in the space area. Thus it was decided to use the Fieldllogger equipment (datalogger) together with the software Superview of the company Novus, which already have reliability in the industrial area as basis for the development of the electronic project. The Fieldlogger has monitoring, control and data logger functions, as well as analog input and digital input and output interfaces, and digital communication.

The entire project described above was constructed and fully qualified for space flight at INPE's facilities. 


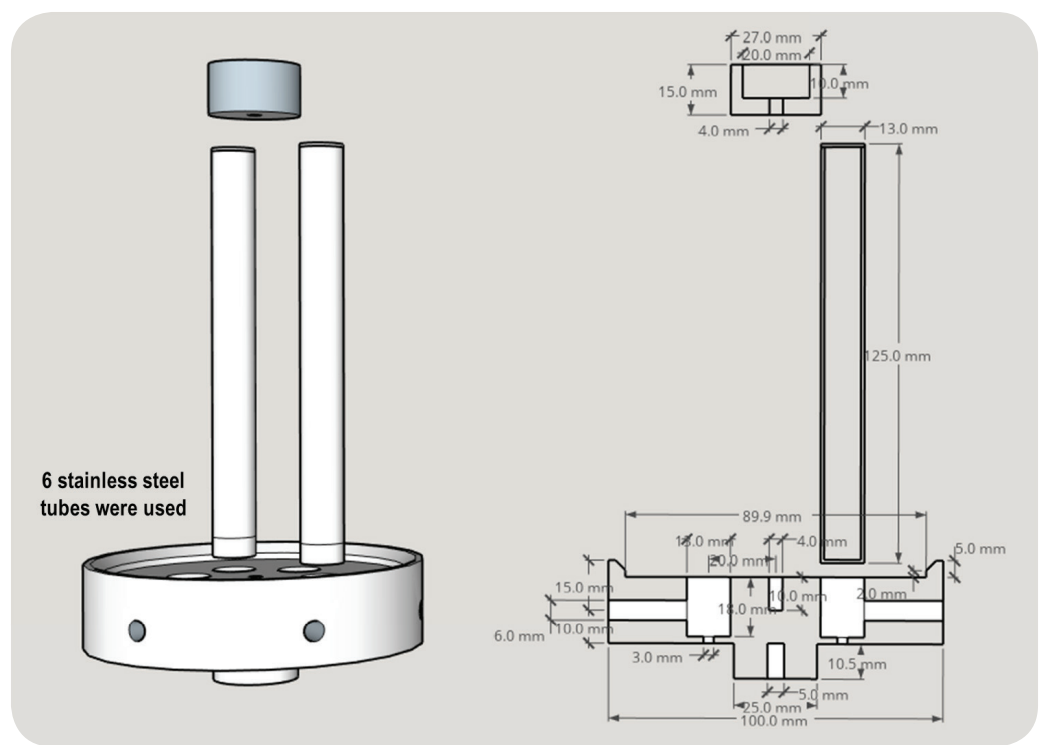

Figure 5. Description of the sample holders.

(a)

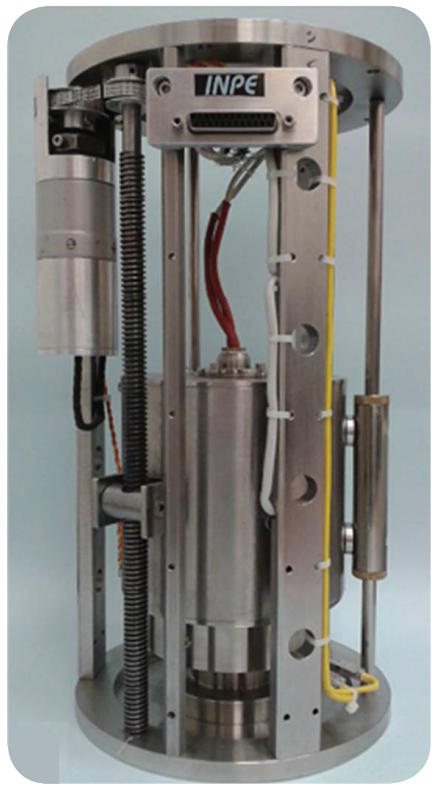

(b)

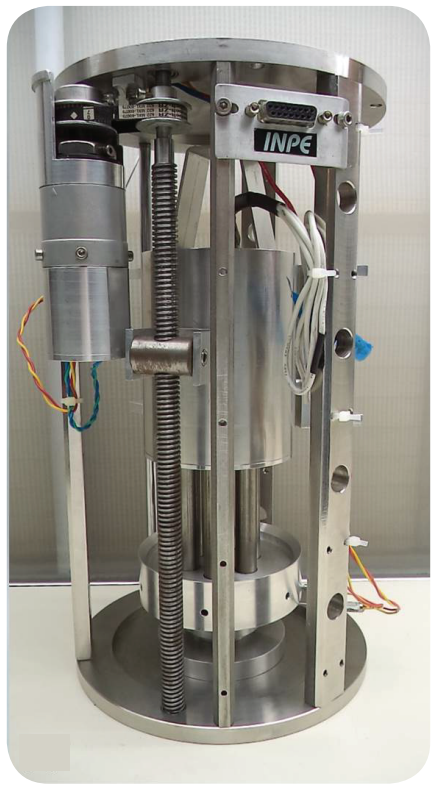

Figure 6. Solidification furnace in its two working phases: (a) at the bottom heating the sample during ground and ascending periods, and (b) at the top permitting a fast sample cooling during microgravity.

\section{EXPERIMENT}

The scientific experiment continues the projects carried out in the previous Announcements of Opportunities and consists of the study of the microgravity influence on the homogeneity of composition and microstructure in the eutectic alloys of binary systems of Bismuth-Tin (melting point of $139^{\circ} \mathrm{C}$ ) and Bismuth-Cadmium (melting at $146^{\circ} \mathrm{C}$ ) solidified in a spatial environment. These alloys can be used in the manufacture of fuses and also as low temperatures weld, and are therefore ideal materials for solidification experiments in environments with temperature limitation. 
Each sample, with $11 \mathrm{~g}$ mass, was sealed under vacuum $\left( \pm 5.10^{-6}\right.$ Torr $)$ within a quartz ampoule with $70 \mathrm{~mm}$ length and $10 \mathrm{~mm}$ diameter, three ampoules of each alloy were made and one of them had an inner cavity to monitor the temperature with a type $\mathrm{K}$ thermocouple, shown in Fig. 7.

(a)

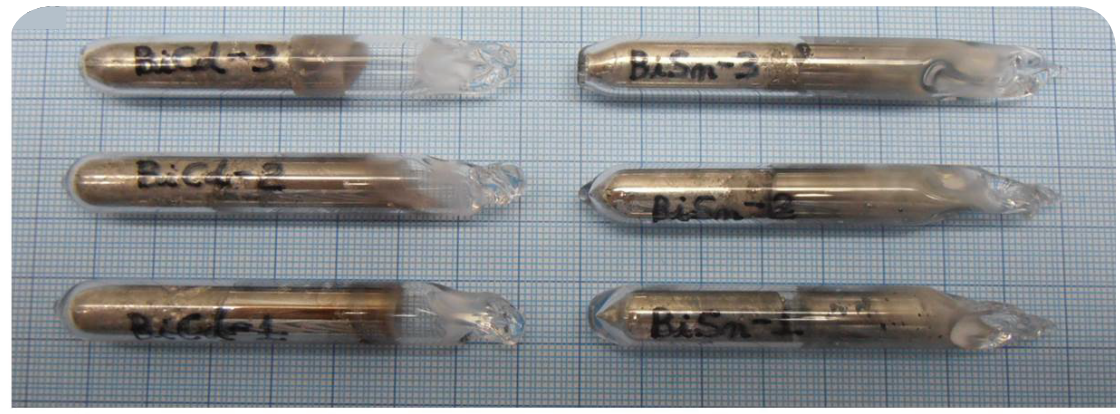

(b)

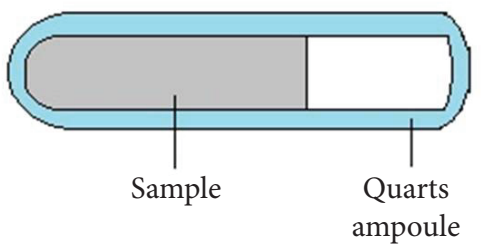

(c)

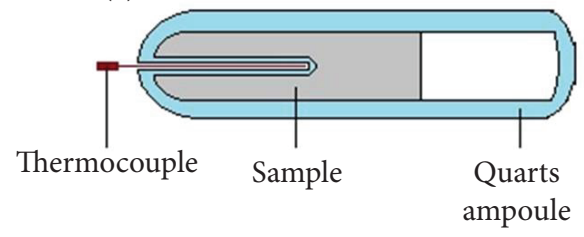

Figure 7. (a) Eutectic BiCd and BiSn ampoules before solidification in the microgravity flight; (b) and (c) Drawings describing the ampoule models.

The thermal cycle of the samples simulating the standard flight procedures of the VSB-30 sounding rocket are shown in Fig. 8. The furnace was heated in the ground to a set point of $165^{\circ} \mathrm{C}$ for $30 \mathrm{~min}$ and switched off about 1 min after (time to reach the microgravity) the furnace hot part was moved to the top of the system, leaving the samples free to cool down (about 6 min).

To complement the in-flight experiment, experiments are also carried out in the LAS permanent laboratory using a $3.5 \mathrm{~m}$ free fall tube (short periods of microgravity) and a furnace coupled to a centrifuge for solidification under macrogravity conditions

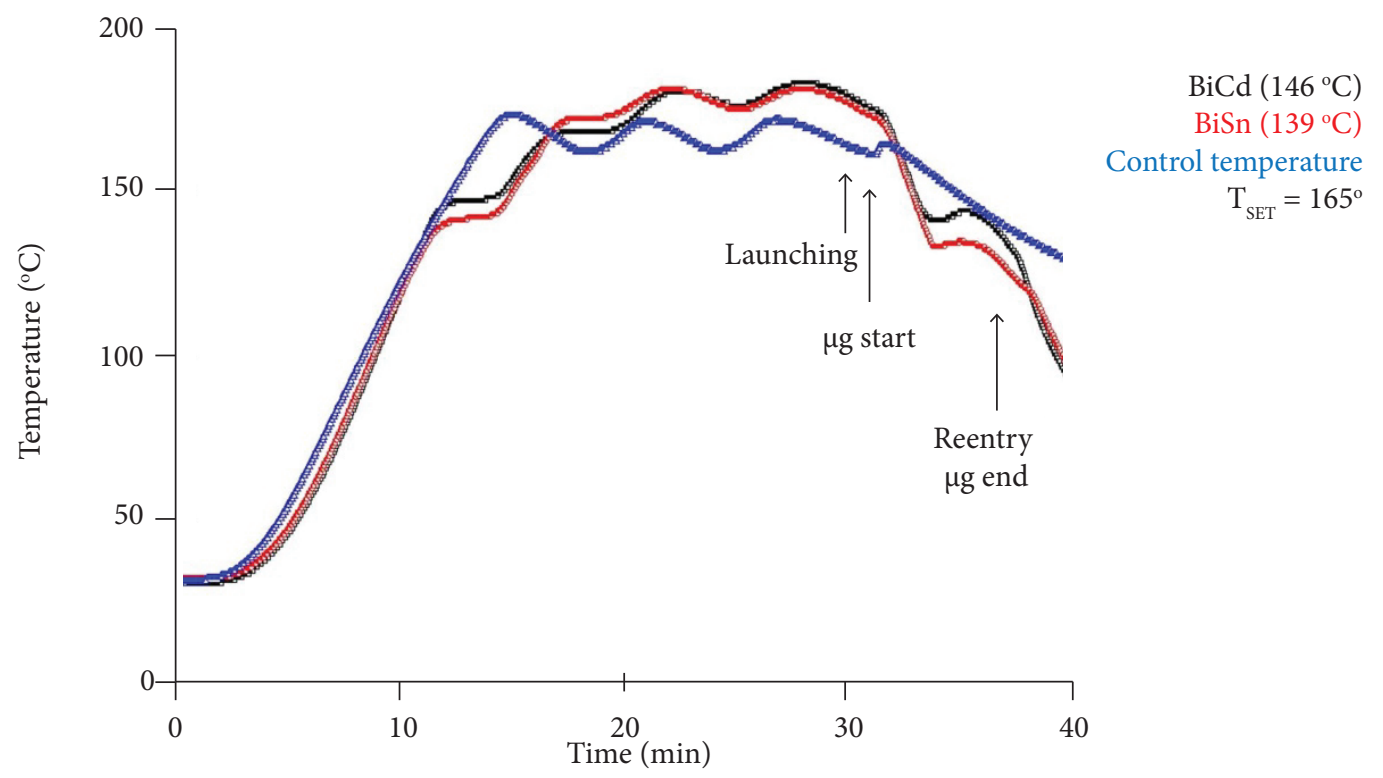

Figure 8. Simulation the solidification furnace thermal cycle during the microgravity flight. 
(gravity $>1 \mathrm{~g}$ ), besides the tests of vertical solidification with normal and inverse configuration. These experiments allow a better understanding of the influence of gravity in the solidification of materials, and also provide subsidies for the choice of materials and in the preparation of experiments to be carried out in sounding rockets or in other vehicles with a longer microgravity time.

The samples will be analyzed and compared with others solidified at ground, using techniques such as densitometry, scanning electron microscopy (SEM) and x-ray dispersive energy spectroscopy (EDS), among others.

\section{THE RIO VERDE MISSION}

The fourth AO flight from AEB had taken place on December 2016 in CLA and was codenamed Rio Verde. A VSB-30 rocket carried ten microgravity experiments from Brazilian universities and research centers (Fig. 9).

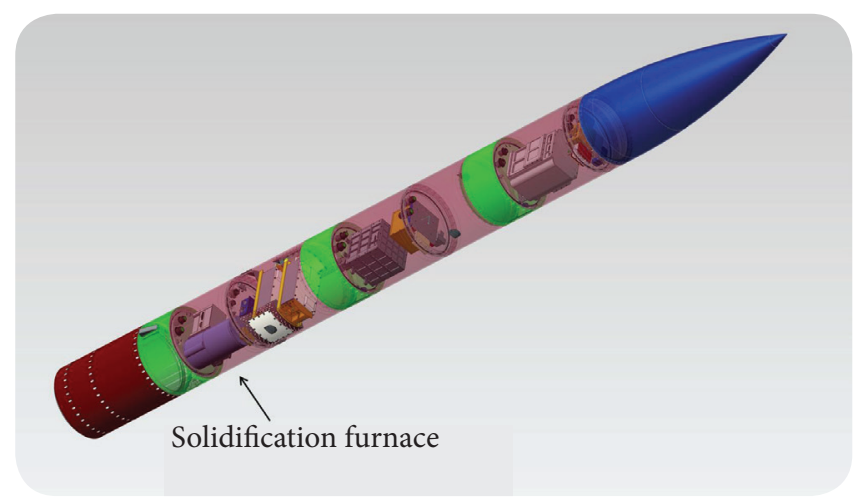

Figure 9. Drawing of the position of the experiments on the VSB-30 payload during the mission.

The apogee of this flight was $44 \mathrm{~km}$ and the total flight time was $11 \mathrm{~min}$ (Fig. 10). Unfortunately, the flight was not successful, mechanical failures (still under analysis by the IAE and DLR/MORABA) caused the separation of the payload of the rocket at the end of the firing of the first stage (approximately $32 \mathrm{~s}$ of flight), so the flight didn't have the expected microgravity period. The payload fell on the sea and was rescued about one hour later. The experiments included the solidification furnace described, made at the LAS/INPE.

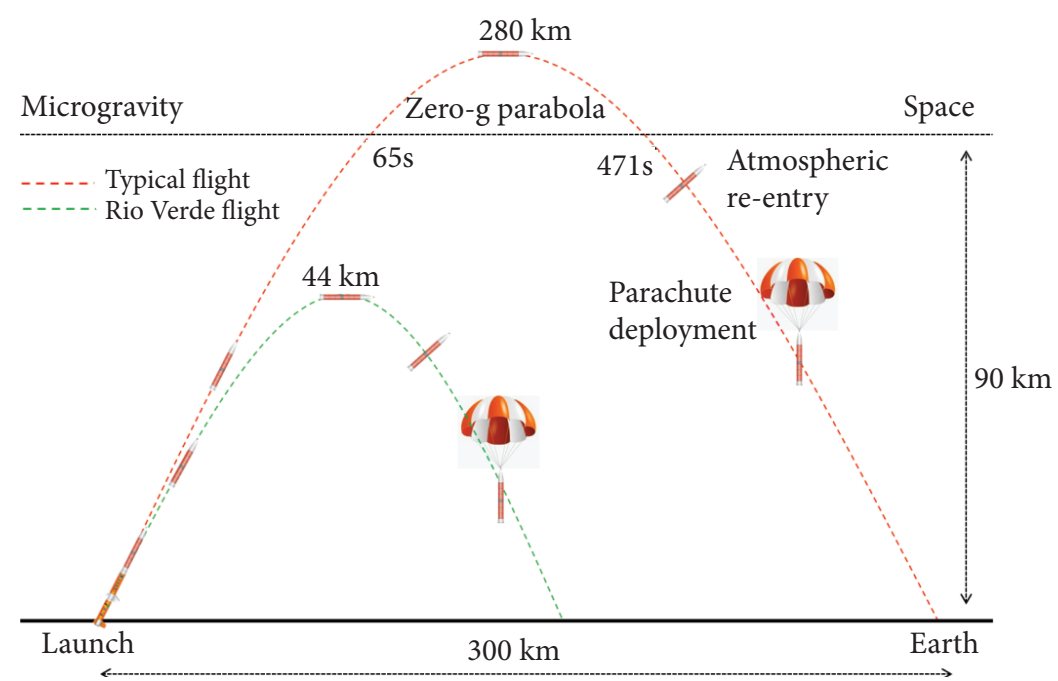

Figure 10. Profile of the flight of the VSB-30 rocket at the Rio Verde mission. 
Despite the atypical flight of the VSB-30, experimenters that did not depend on the microgravity period for the operation of their experiments had good results.

With the recovery of the payload, it was observed that sea water entered the module in which the oven was installed, which could cause damages in the electrical parts of the experiments of this module (Fig. 11). Probably due to the abrupt movements during the separation of the useful load at the end of the firing of the first stage the VSB-30 rocket impaired the module seal, which caused the entrance of water after the impact in the sea.

(a)

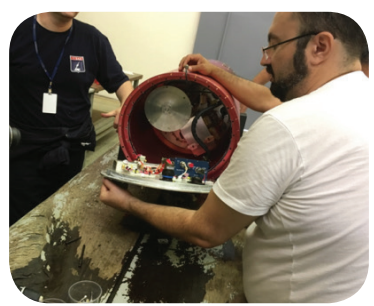

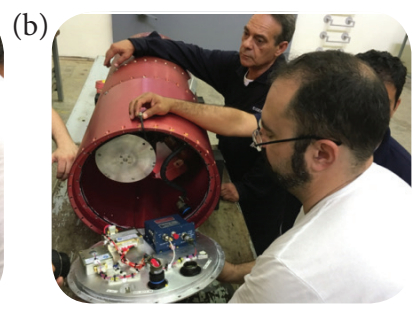

(d)

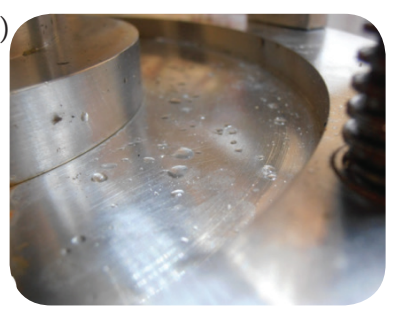

Figure 11. (a), (b) and (c) payload module with sea water; and (d) furnace solidification.

It was also observed that the atypical flight, with accelerations higher than expected (13 g during the ascendant flight), caused structural damage to the solidification furnace: the furnace fixing screws on the VSB-30 module plate, even with chemical lock, were loosened; one fixing screw and the sliding bar were flexed; the adjustment screw of the furnace and the control thermocouple were broken; and the position sensor (limit switch) was damaged (Figs. 12 and 13). However, the electrical system and the developed software presented satisfactory results, qualifying them for use in the next flights.

(a)

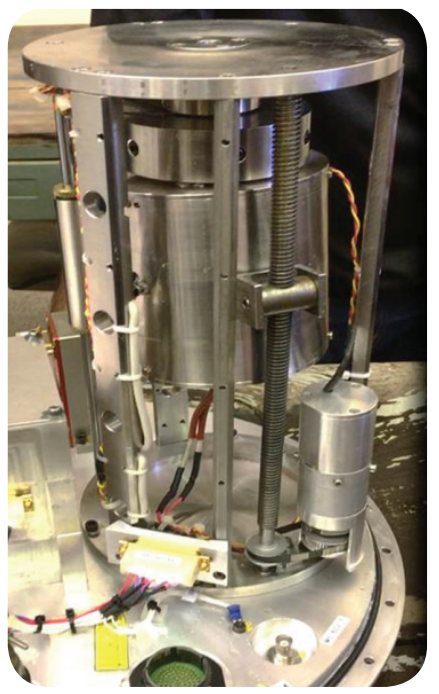

(b)

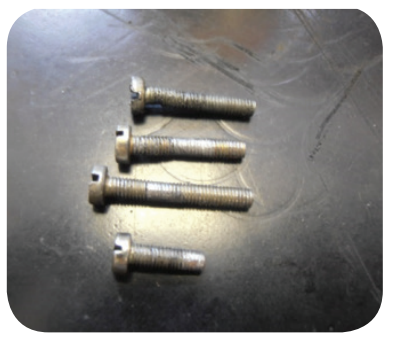

(c)

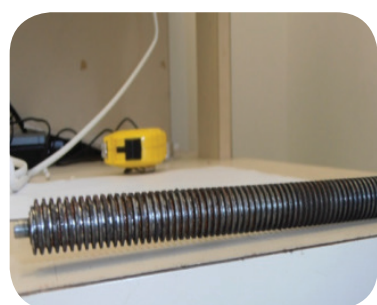

Figure 12. (a) Solidification furnace fixed to the plate of VSB-30 after the flight; (b) furnace fixing screws; and (c) the sliding bar flexed.

The flight data for the furnace thermal cycle for both samples and the ambient temperature within the module obtained by the UEFOG fieldlogger are shown in Fig. 14.

The cycle behavior was similar as simulated, even though the oven did not move to the upper position during the flight; there was the temperature drop required for solidification of the BiSn and BiCd samples during the Rio Verde flight period (about $11 \mathrm{~min}$ ).

It was also observed in Fig. 14 that the general temperature of the module where the furnace was located remained throughout the experiment at about ambient temperature $\left(25^{\circ} \mathrm{C}\right)$, which was one of the concerns of the researchers, once several experiments, 
including biological ones, were close, the insulation has to be good enough to keep the module external walls inside the acceptable limit.

The proposed scientific experiment, the solidification of eutectic alloys, can't be evaluated on this flight since the microgravity period didn't occur.

(a)
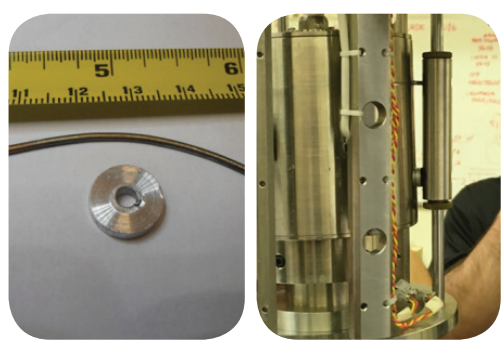

(b)

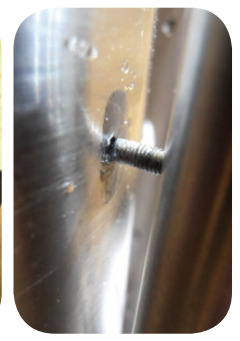

(c)
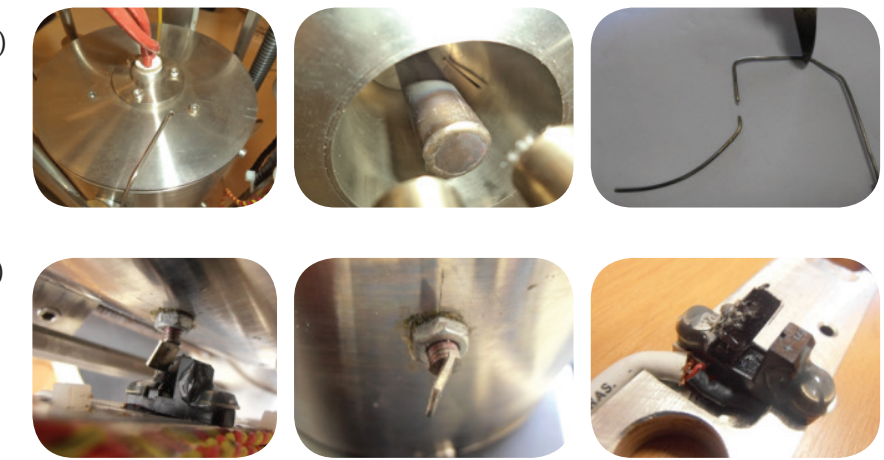

Figure 13. (a) Adjustment screw; (b) control thermocouple broken; and (c) damaged position sensor (limit switch).

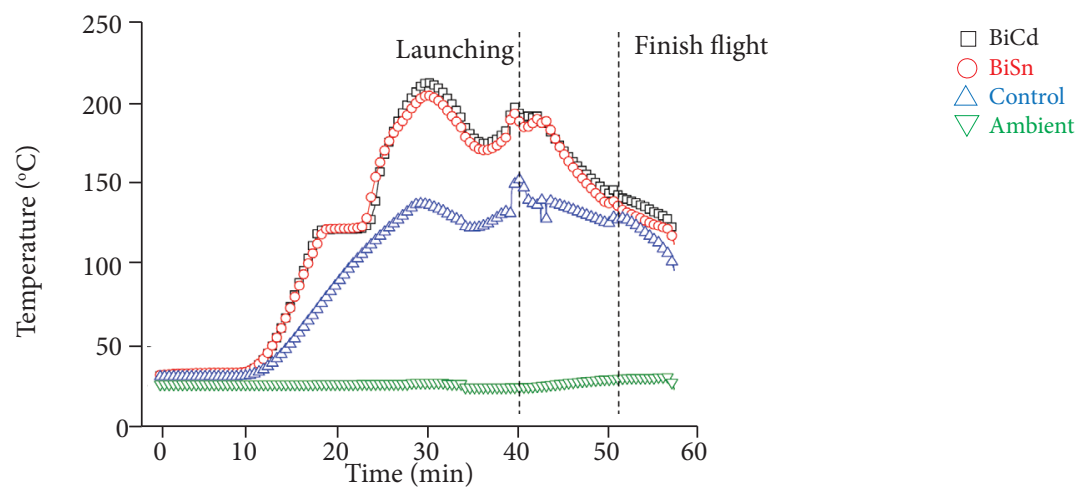

Figure 14. The solidification furnace thermal cycle during the Rio Verde flight.

\section{CONCLUSIONS}

The solidification furnace, provided by LABAS/INPE to the Brazilian sounding rocket program, presents an appropriate thermal mass to achieve rapid cooling time by conduction and radiation consistent with the short flight duration, and its electronic and mechanical components performed with precision and reliability during the flight qualification tests. The atypical flight that occurred during the Rio Verde Mission did not allow to accurately qualifying the electronic and mechanical systems of the furnace, although they have responded satisfactorily to the failures occasioned. As for the scientific findings, no results were obtained, since the microgravity period expected in the flight did not occur.

\section{AUTHOR'S CONTRIBUTION}

Conceptualization, Toledo RC, Ribeiro MF, Bandeira IN and An CY; Methodology, Bandeira IN and An CY; Investigation, Toledo RC, Ribeiro MF, Bandeira IN and An CY; Writing - Original Draft, Toledo RC; Writing - Review, Bandeira IN and An CY; Funding Acquisition, Bandeira IN and An CY; Resources, Bandeira IN and An CY; Supervision, An CY. 


\section{FUNDING}

Agência Espacial Brasileira [https://doi.org/10.13039/501100008138]

Grant No. \#1042006130

Coordenação de Aperfeiçoamento de Pessoal de Nível Superior [http://dx.doi.org/10.13039/501100002322]

Grant No. \#88882.317522/2019-01

\section{REFERENCES}

Agência Espacial Brasileira (2012) Programa Nacional de Atividades Espaciais - PNAE: 2012-2021. Brasília: Ministério da Ciência, Tecnologia e Inovação, Agência Espacial Brasileira.

An CY, Boschetti C, Ribeiro MF, Toledo RC, Freitas FE, Bandeira IN (2011) Performance of a solidification furnace developed for sounding rockets. Microgravity Science and Technology 23(4):427-432. https://doi.org/10.1007/s12217-011-9263-8

An CY, Boschetti C, Ribeiro MF, Toledo RC, Freitas FE, Castilho FF, Bandeira IN (2012) Solidification furnace for microgravity experiments on sounding rockets. J Aerosp Technol Manag 4(2):237-240. https://doi.org/10.5028/JATM.2012.04021412

An CY, Toledo RC, Boschetti C, Ribeiro MF, Bandeira IN (2014) Solidification of lead tin and lead telluride eutectic alloys in microgravity. Microgravity Science and Technology 25(5):267-273. https://doi.org/10.1007/s12217-013-9348-7

Bandeira IN, Bogossian 0, Correa F (2007) Centenary mission: First brazilian microgravity experiments at iss. Microgravity Science and Technology 19(5-6):42-48. https://doi.org/10.1007/BF02919451

Garcia A, Yamanaka SSC, Barbosa AN, Bizarria FCP, Jung W, Scheuerpflug F (2011) VSB-30 sounding rocket: history of flight performance. J Aerosp Technol Manag 3(3):325-330. https://doi.org/10.5028/jatm.2011.03032211

Hamacher H, Fitton B, Kingdon J (1987) The environment of earth-orbiting systems. In: Walter HU, editor. Fluid sciences and materials science in space: a European perspective. Berlin: Springer.

Naumann RJ, Herring HW (1980) Materials processing in space: early experiments. Washington: NASA. Scientic and Technical Information Branch.

Toledo RC (2013) Study of solidification of eutectic alloys in microgravity environment (PhD Thesis). São José dos Campos: INPE. In Portuguese. 